Papers and Proceedings of the Royal Society of Tasmania, Volume 115, 1981

(ms. received 24.3 .1980 )

\title{
CONSERVATION OF THE MOUNT CAMERON WEST ENGRAVING SITE,
} NORTHWESTERN TASMANIA

by P.J. Hughes, A.L. Watchman and M.E. Sullivan

Department of Prehistory, Australian National University, Canberra, ACT

(with two tables, one text-figure and two plates)

https://doi.org/10.26749/rstpp.115.211

HUGHeS, P.J., WATChMAN, A.L. and SULLIVAN, M.E., 1981 (30 ix): Conservation of the

Mount Cameron west engraving site, northwestern Tasmania. Pap. Proc. R. Soc. Tasm.,

115, 211-222 (with one figure and two plates). ISSN 0080-4703. Department of

Prehistory, Australian National University, Canberra, A.C.T., Australia.

A study of the site and its surroundings indicates that the geochemical environment is such that although the aeolian calcarenite on which the engravings are executed is soft an friable, it is not underoing appreciable chemical or physical weathering, at least in the short-term. In contrast the site is under considerable threat from coastal erosion. This threat could be reduced, if not eliminated, through the implementation of coastal erosion control measures.

\section{INTRODUCTION}

The Mount Cameron West Aboriginal Site in northwestern Tasmania contains a set of engravings widely regarded as being of international cultural significance. The land on which the site occurs was acquired by the National Parks and Wildlife Service of Tasmania in February 1977 and was proclaimed a State Reserve in June 1978. Ultimately the Service will prepare a long-term programme for the conservation, presentation and interpretation of the site. As a step towards this goal we have undertaken, on a consultancy basis, a preliminary geological and geomorphological investigation in relation to the deterioration, conservation and management of the site (Hughes, Watchman and Sullivan 1979), the results of which are reported in this paper.

The fieldwork for this project was carried out with the assistance of G. Melville, Ranger, North-West Region, in July 1979. Field observations were made of the engraving site and its surroundings, and samples of rock and sand were collected for mineralogical, physical and chemical analyses at the Australian National University.

The findings of this study are based not only on the results of this fieldwork and the subsequent analyses, but also on a review of published and unpublished documents relating to the site and extensive discussions with Dr Rhys Jones, Department of Prehistory, Research School of Pacific Studies, ANU, and with Professor Bruce Thom, Department of Geography, Royal Military College, Duntroon.

\section{PHYSICAL SETTING}

The rock engravings are on two outcrops of aeolian calcarenite at the northern end of a $3 \mathrm{~km}$ long sandy beach (fig. 1). The southern outcrop is separated from that to the north by a gully about $200 \mathrm{~m}$ wide which is partly filled with sand. This outcrop lies immediately behind the foredune and within an active blowout and is now almost completely buried in mobile sand. Because of this we are unable to comment on conservation problems specific to this outcrop.

The northern outcrop forms a prominent bluff about $6 \mathrm{~m} \mathrm{high} \mathrm{(plate} \mathrm{1)} \mathrm{and} \mathrm{the}$ engravings have been executed both on the cliff face and on slabs fallen from the face now forming a talus deposit between the foot of the cliff and the present high tide limit. Most of the block talus deposit with its engravings is now buried in sand, presumably that used to cover the site in 1971 (McCarthy n.d., p.17). At present only panel 24, the top 


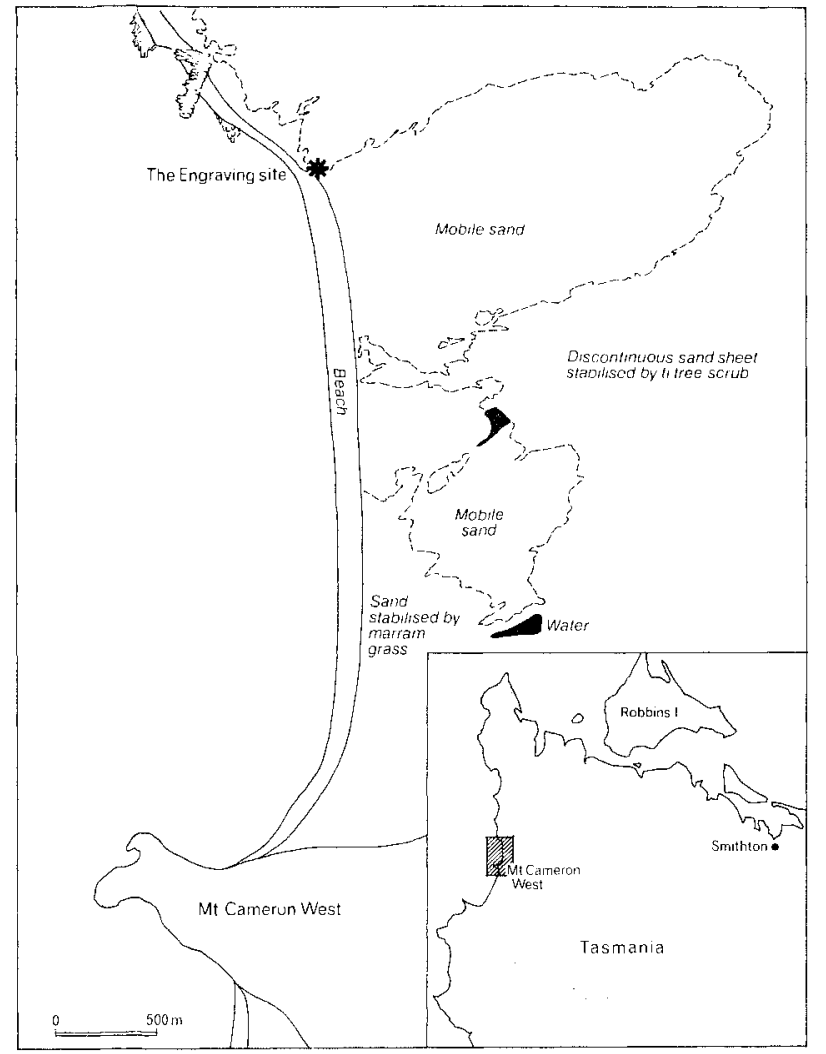

FIG. 1.- Location and setting of the Mount Cameron West engraving site. Map drawn from an aerial photograph taken in February 1979. of panel 13, and part of panel 1 are still exposed (the numbering system used to identify the engraved panels is that of Luckman (1951a and b) as modified by McCarthy (n.d., p.20). A wire fence has been constructed around the site to exclude stock, and marram grass has been extensively planted to stabilise the sand cover and to encourage further sand trapping.

Behind and to the south of the site is an active eastnortheast trending blowout $1 \mathrm{~km}$ across and 2 $\mathrm{km}$ long, the northern limit of which extends inland from behind the main (north) engraving site.

The climate of the region is temperate marine, and the average annual rainfall is about $1150 \mathrm{~mm}$ (Richley 1978). Al though rainfall is greatest in winter, there is no dry period. January has the lowest average monthly rainfall (with about $45 \mathrm{~mm}$ at Marrawah) and as it is at this time that potential evaporation is highest, evaporation may then exceed rainfall. Hence during the height of summer the calcarenite and its loose sand cover may dry out. Onshore winds predominate, and are commonly strong.

\section{PREVIOUS INVESTIGATIONS}

It is generally agreed that the site was covered by sand with a thick tea-tree and other scrub cover in the early 1830s when George Augustus

Robinson passed close by several times (Jones in press, McCarthy n.d., p.3). It is likely that this sand cover remained until shortly before the site was reported to Meston in the early $1930 \mathrm{~s}$ (Meston 1933, 1934). Since that time several people have commented on the state of preservation, and problems of conservation of the site.

Meston commented that the 'friable calcareous sandstone is soft and easily worked, but hardens on contact with the air. In consequence of its friable nature many of the carvings are badly weathered, and al1 show marks of erosion' (Meston 1933, p.2). Elsewhere (1934, p.182) he noted that 'one mass...(is)...entirely covered with motifs, some badly weathered, others in a good state of preservation'. Although in his study Meston examined both outcrops, these comments refer mainly to the southern outcrop, which at that time was almost totally stripped of sand.

Luckman first visited the area in 1949 and noted that one of the pane1s in the southern outcrop, described by Meston, was 'in an advanced state of erosion' (195la, p.2). One year later, when he returned to the site, he found that same panel had broken into three pieces, and that the whole engraved surface had flaked away from the main block (1951a, p.2).

Luckman then undertook a further study of the northern outcrop which involved 


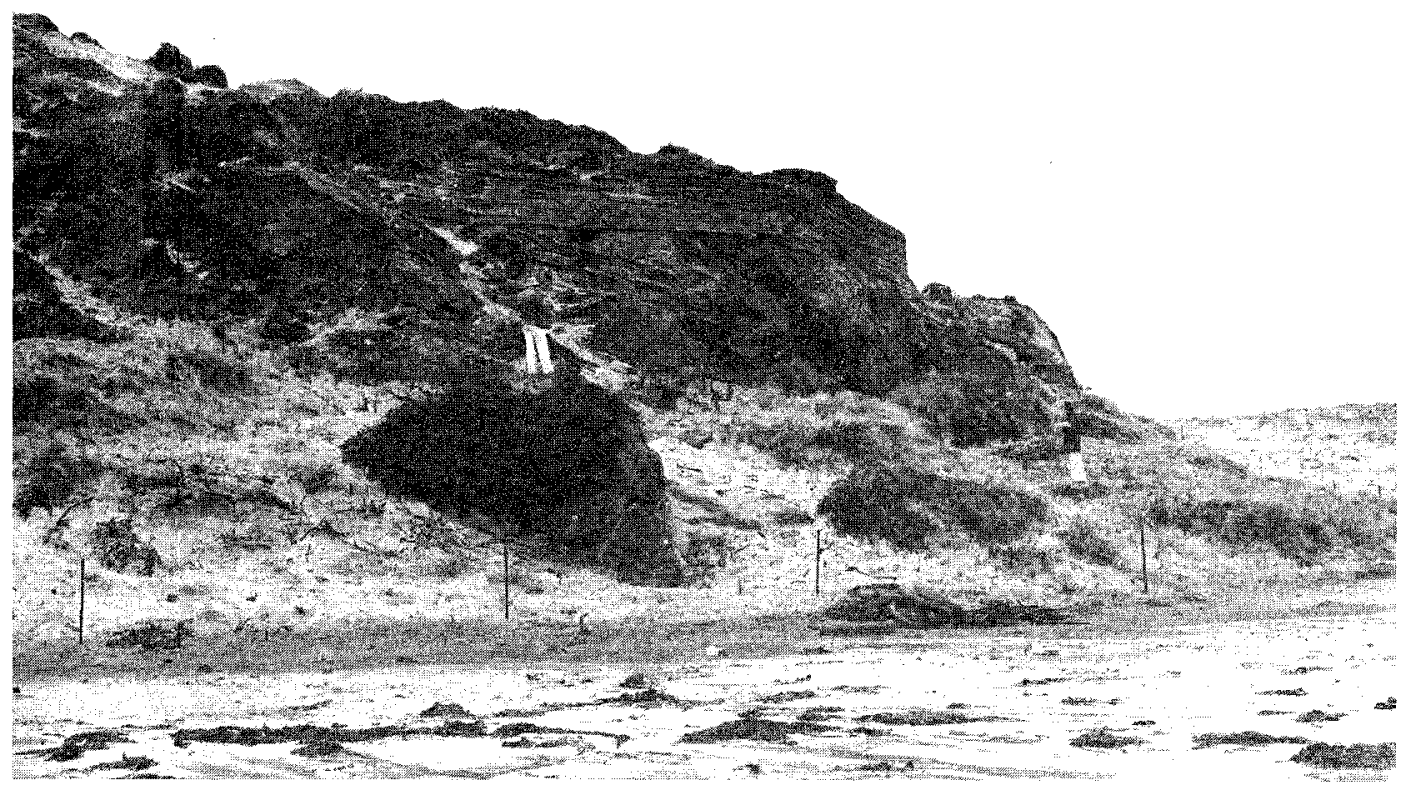

PLATE 1.- The northern outcrop of the Mount Cameron West Aboriginal site showing the partial sand cover and the close proximity of the high tide limit. The blowout is in the right background.

extensive removal of the sand covering the engraved blocks forming the talus deposit at the foot of the cliff. He noted that 'where the covering sand was damp, particularly on horizontal surfaces, erosion was so advanced that the carved rock had literally merged into the sand itself, while those carvings which had become covered with vegetation flaked off through the penetration into the sandstone layers of countless fine rootlets' (195la, p.6).

In 1969 Jones and Lourandos undertook a major archaeological study of the site and McCarthy recorded the engravings in detail. The results of the archaeological study indicate that the engravings were completed before 1350BP, that from that time until about $850 \mathrm{BP}$ the site was used as a campsite, and that after 850BP the site was abandoned and became covered with sand and scrub (Jones in press). At that time Jones observed that when initially excavated the aeolian calcarenite was extremely soft, but hardened when exposed to the air such that after five days it was able to withstand the pressure of casting.

In his report on the rock engravings recorded in this study, McCarthy (n.d., p.10-20) has compiled a list of opinions on, and suggestions for the conservation of the engravings expressed since 1931 (including those of Meston and Luckman), none of which, he notes, has been heeded or acted upon by the relevant authorities. The solutions proposed for conserving the engravings depend upon what is perceived to be the major threat to their survival; generally either physical or chemical disintegration of the rock, or destruction by storm wave erosion, or occasionally both. In all instances the only 
permanent solution offered is that the engraved panels be sawn off and removed for safekeeping to museums. Other solutions proposed to protect the engravings in situ include the stabilisation of the rock surfaces with surface consolidants and the construction of a sea-wall or a protective foredune.

\section{RESULTS OF THIS INVESTIGATION}

The geology of the site

Methods -

Field descriptions were made of the site, particularly its geology and geomorphology, and the nature and condition of the rock surface and its engravings. In order to observe the condition of the rock and the engravings below the surface of the protective cover of loose sand, a small pit, about $0.5 \mathrm{~m}$ deep was dug adjacent to panel 13 . Samples of the rock, of a gelatinous precipitate exuding from a number of pits and fissures in the rock, and of unconsolidated sand from on and around the site were collected and subsequently analysed.

The field pH of each sample of unconsolidated sand was measured to the nearest 0.5 of a pH unit using a CSIRO Soil pH Test Kit. The calcium carbonate contents of both the rock samples and samples of unconsolidated sand were determined in the laboratory using the rapid gravimetric method of Bauer, Beckett and Bie (1972). The air-dry colour of each sample was determined in the laboratory using a Munsell colour chart.

The grain size of the unconsolidated sands was determined by dry sieving (Folk 1974) and their mineralogy and grain morphology by examination under a binocular microscope. $X$-ray diffraction (XRD), infrared spectroscopy (IRS) and X-ray fluorescence (XRF) analyses were also carried out on the sands, to determine their chemical compositions and constituent minerals.

Four samples of the rock were analysed. Two were collected during this study from exposed surfaces; one from the cliff face and the other from the boulder on which the engraved panel 1 is executed. The other two were originally collected by Jones during the 1969 excavations, and came from beneath the sand mantle. Al1 rock samples were thin-sectioned and petrographic descriptions were made. The mineralogy and grain morphology of the acid insoluble residues of these samples were also described, XRD and IBS we re carried out on the rock samples to determine the precise compositions of their constituent carbonates and associated salts. Detailed scanning electron microscope studies of the surface layers of the samples collected from the exposed cliff face and boulder were carried out to determine the nature of the weathering crust. The two samples collected by Jones were also analysed by XRF for major elements. The composition of the gelatinous exudation from the rock was determined by XRD and IRS.

The major element contents of the samples of sand and of buried rock collected by Jones were analysed by XRF according to the method of Norrish and Hutton (1969). The volatile components (water and carbon dioxide) and sodium cannot be measured by this method and the results were therefore calculated on a volatile and sodium-free basis (table 2b). When these analyses are recalculated on a quartz-free basis with all totals to $100 \%$ (table 2b) they give a good indication of the relative geochemical environments of the sand and the buried calcarenite.

Composition of tho rock and the uncoisolidated sand .

The rock on which the engravings are executed is aeolian calcarenite. This calcarenite consists of well-rounded shell fragments up to $1 \mathrm{~mm}$ in length, and occasional quartz grains, set in a sparse matrix of very finely divided shell and some secondary calcite (plate 2a and table 1). The shell fragments are randomly oriented except where bedding is strongly developed, in which case they tend to be aljgned sub-parallel to the bedding. Locally thin beds, on average $30 \mathrm{~mm}$ thick, are internally graded with coarser fragments at the base and finer fragnents at the top. The finer-grained portions of such beds are more resistant to weathering, standing out in sharp relief on weathered surfaces. In all instances the acid insoluble residus, which is between 7 and $25 \%$ of 


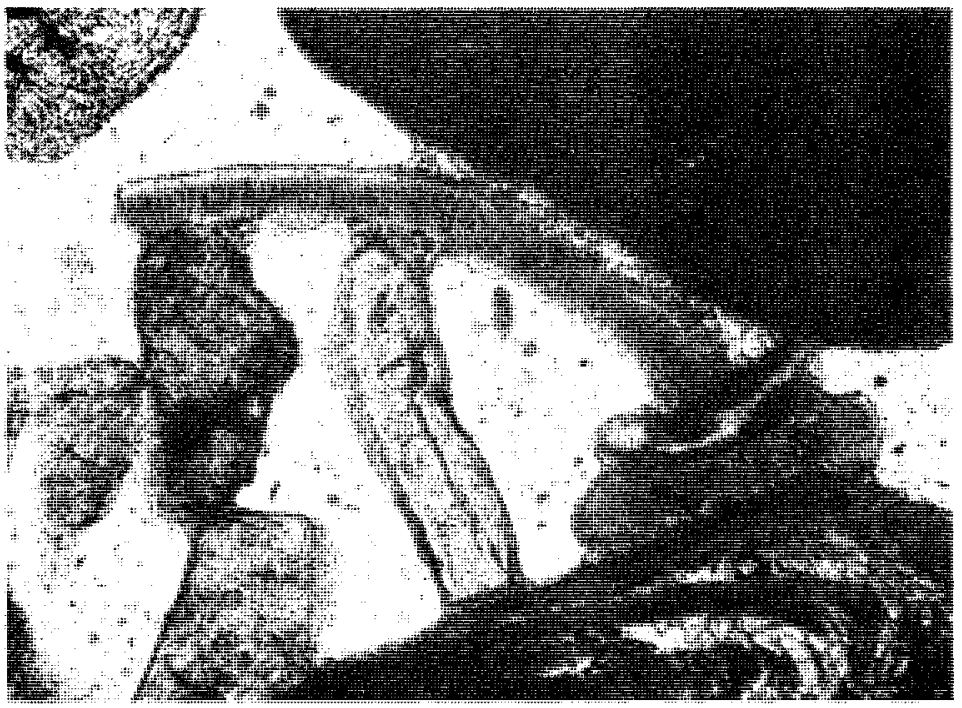

PLATE 2a.- Thin section of fresh aeolian calcarenite under plane polarised light $x 60$. Note elongated shell fragments and high proportion of voids. Shell fragments thinly coated with secondary calcite which acts as a weak cement at the point of contact.

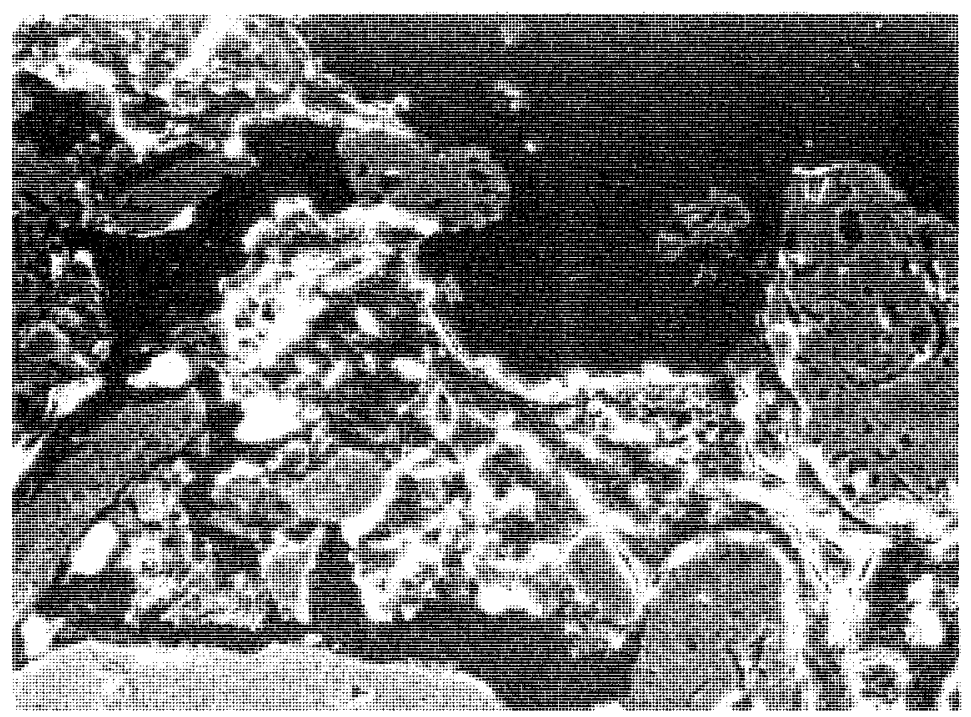

PLATE 2b.- Scanning electron microscope photograph of surface layer of aeolian calcarenite $x$ 100. The poorly laminated cementing medium binding the fragments of shell and quartz (light grey) is gelatinous calcium magnesium sulphate. The homogenous dark grey zones are voids in the rock. 
LOCATION, PH AND CARBONATE CONTENT OF SAMPLES

Sample No

Loose sand

$\mathrm{MCW} 6$

MCW 7

MCW 8

MCW 9

MCW 10

MCW 11

MCW 13

MCW 14

MCW 15

MCW 1969/1

MCW $1969 / 2$
$\mathrm{pH}$

$: \mathrm{CaCO}_{3}$

8.5

7.5

7.5

$7.0-7.5$

6.5

$7.0-7.5$

7.0
18

19

21

(1)

Location

Surface sample (wet) from against engraved calcarenite pane1 13 Sample from $20 \mathrm{~cm}$ below the surface (damp) and against

engraved calcarenite pane 13.

Surface sample (wet) $30 \mathrm{~cm}$ out from calcarenite panel 13.

Sample from $20 \mathrm{~cm}$ below surface sample MCW 8 (damp).

surface sample (damp) $4 \mathrm{~m}$ seawards of MCH 6 to 9 and

sloping foredune.

Surface sample from base of foredune (wet) $1 \mathrm{~m}$ from fresh high ticle strandline.

Surface sample (damp) of sand resting on the top of the cliff.

Surface sand from backbeach within the tidal zone.

Sand from $20 \mathrm{~cm}$ below the surface at same spot.

Terra rosa soil exposed in the gully to the south of the main

Sample from cliff face to the south of main gallery.

Sample from boulder with engraved panel no. 1.

Sample collected by Jones from the excavations.

Sample collected by Jones from the excavations. 


\section{P.J. Hughes, A.L. Watchman and M.E. Sullivan}

the weight of the rock, consists of fine sand, dominantly well-rounded to subangular frosted quartz. The surfaces of most of the quartz grains are bleached white, but some are iron stained a very pale brown (10 YR 7/3) colour. There are minor amounts of dark coloured minerals and rock fragments, but no siliceous marine organisms.

The rock is highly porous and permeable and its cohesiveness results from the sandsized grains being embedded in a small amount of finely-divided shell, and partially cemented by secondary calcite. This clear calcite is developed along the interfaces between grains, and is generally less than $0.1 \mathrm{~mm}$ in thickness (plate $2 \mathrm{a}$ ). The cement is not uniformly developed throughout the rock, but occurs randomly, and may reflect the trapping of carbonate-rich fluids from which calcite has subsequently precipitated. Locally but sparsely, secondary calcite is well developed, and the crystals fill pore spaces, strongly binding shell fragments and quartz grains. Because of the sporadic occurrence of the cement binding the grains the rock is potentially susceptible to granular disintegration on pressure of contact. However much of the rock surface is rendered nore stable by a dark crust, about $1 \mathrm{~mm}$ thick, developed where the rock is directly exposed to subaerial weathering.

Under the microscope the dark surface crust is seen to consist of calcarenite in which the pore spaces are partially filled with a gelatinous inorganic cement which supports a growth of dark algal-like organic material. Scanning electron microscopic examination and IRS analyses of this cement show that it is complex hydrated calcium magnesium sulphate with possibly some dolomite and calcium sulphate (plate 2b). As this sulphate cement is relatively insoluble it accumulates at the surface and the crust so formed provides a protective coating inhibiting granular disintegration of the underlying rock. The cement forms from the reaction between sulphate ions in the sea-spray (based on an analysis of southern ocean seawater by Taylor 1975) and carbonate ions in the shel1. In a process similar to dolomitization of aeolianite described by Muller and Tietz (1966), magnesium ions in the sea-spray displace calcium ions released as calcium carbonate dissolves.

On slightly sheltered parts of the cliff the rock surface is pitted as a result of granular disintegration following removal of the calcite cement in solution by groundwater seepage. Within and around some of these pits and along fissures in the rock, a gel-like salt encrustation occurs. This gel is a complex hydrated calcium magnesium sulphate, like the surface cement described above. On drying in the laboratory, the gel crystallises into a hard compact mass. As the drying process is slow and requires low humidity, the formation of a hard cement from this gel probably rarely occurs in the natural environment where the rock remains damp from sea-spray and rain. The partial drying of this gelatinous hydrated calcium magnesium sulphate at the surface of the rock when exposed to the air is taken to be the major cause of the surface hardening noted by veston (1933) and Jones.

Samples of unconsolidated sand taken from adjacent to the buried engravings and from other localities at varying distances from the rock face (table 1 ) were analysed (table 2) in order to characterise the sands, to determine whether the loose sand mantle provides an environment conducive to the preservation of the buried engravings, and to assess the extent to which any interaction has occurred between the sand and the rock face.

A11 the sand samples consisted of well-sorted fine sand with less than $0.5 \%$ silt + clay. All comprise predominantly we11-rounded quartz grains with varying amounts of recent well-rounded shell fragments, which make up the carbonate content. Sample MCW 9 contained, in addition, some very coarse sand made up of recent shell fragments and fragments of calcarenite. The quartz grains are very slightly to moderately stained with iron oxide, and this imparts a pale to very pale brown $(10 \mathrm{YR} 6 / 3-7 / 3)$ colour to the sands.

The carbonate in all but one of the samples is composed of low-magnesium calcite. In contrast, sample $\mathrm{MCW} 7$, from adjacent to the buried calcarenite panel 13 , contained in 
XRF ANALYSES OF SAND AND CALCARENITE SAMPLES

2a volatile and sodium-free basis

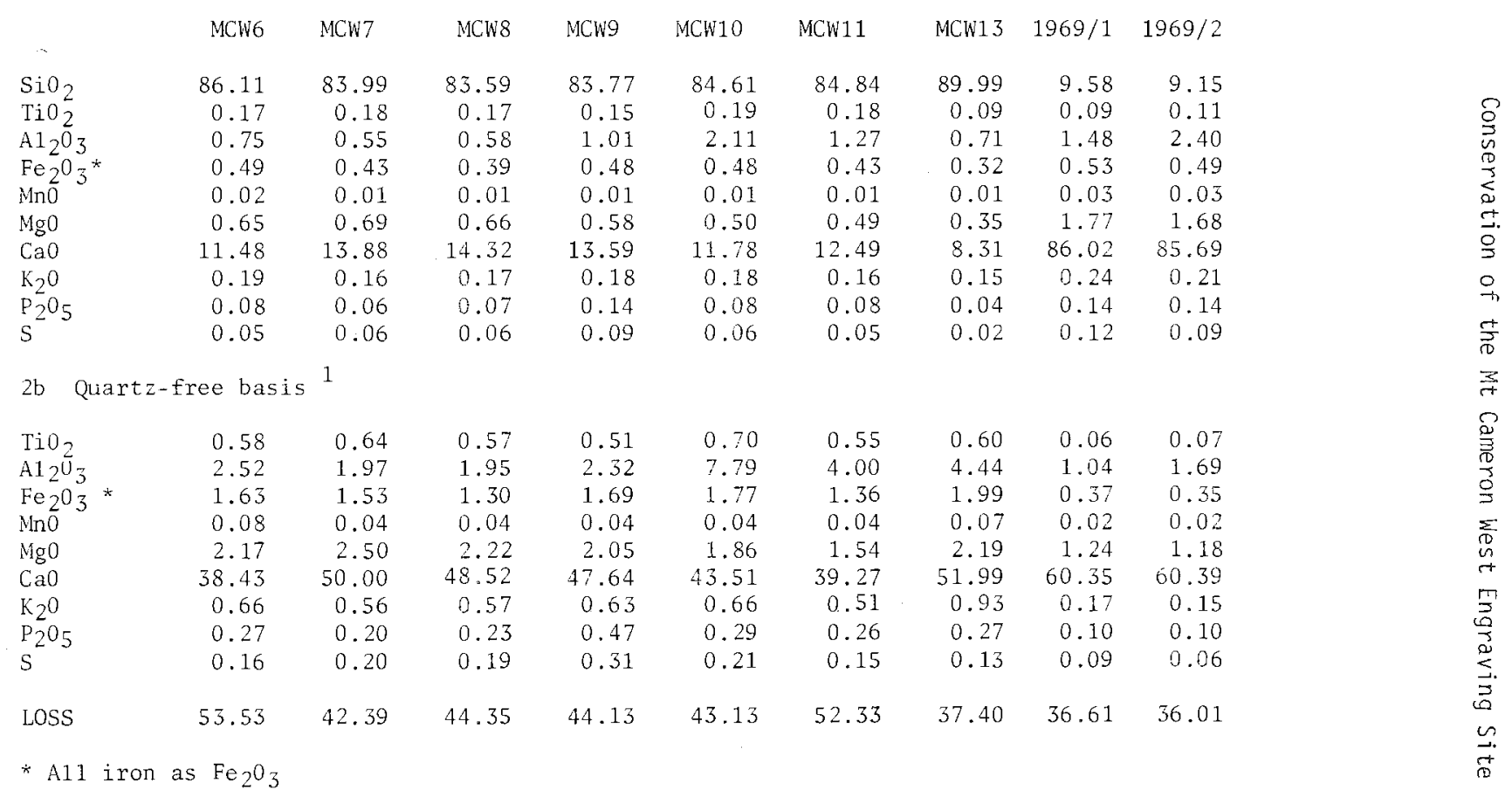

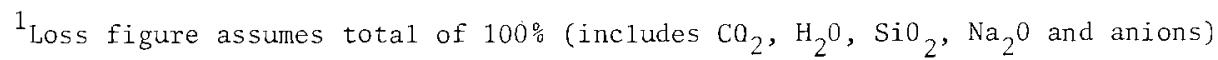


addition high-magnesium calcite and dolomite. This magnesium is most likely derived from sea-spray, either washed downwards through the sand or percolating through the porous rock and accumulating at the rock/sand interface. Dolomitization of aeolianite by the dowaward percolation of solutions with a high $\mathrm{Mg} / \mathrm{Ca}$ ratio in coastal supratidal and spray zones has been described by Adams and Rhodes (1960) and Shinn and Ginsberg (1964). These magnesium-rich compounds are both relatively insoluble and chemically compatible with the calcarenite.

The absence of pieces of calcarenite in the sand samples taken from against the buried rock face (MCW 6 and 7) shows that the buried calcarenite is mechanically stable, and is not undergoing physical disintegration. The gravel-sized fragments of fresh shell and ealcarenite in sample MCW 9 were probably incorporated when the engravings were covered with sand in 1971.

The geochenical environment -

The aeolian calcarenite is highly porous and poorly cemented, and consequently friable. However the high porosity and the fact that it consists mainly of calcium carbonate enhance its chemical stability in two ways.

Firstly the close proximity of the site to an exposed coastline means that large quantities of salts from sea-spray are deposited on the site. Such salts, particularly the efflorescent sodium chloride, could cause potentially harmful salt weathering, as in other coastal areas in Australia (Hughes 1978, p.36). However damage from salt weathering is negligible since in this area of high and frequent rainfall, such soluble salts are readily flushed through the porous rock and loose sand cover, and thus removed from the site.

Secondly because the rock contains a high proportion of calcium carbonate, slightly acidic or chemically neutral rainwater quickly becomes alkali-saturated, and ceases to be chemically aggressive.

In addition the geochemical environment of the exposed calcarenite is such that magnesium and sulphate ions in the sea-spray react with the calcium carbonate in the rock to form, especially at the rock surface, a protective insoluble cement, which nevertheless only partially fills the pore spaces.

The fact that the rock is porous, allowing potentially harmful salts to be flushed out, has been a major factor in the survival of the engravings. Any attempt to further stabilise the rock face by the use of surface consolidants would almost certainly result in a considerable reduction in the porosity of the rock surface. This in turn would allow the accumulation of harmful salts, in particular sodium chloride, behind the impregnated rock face, with the ultimate effect of alternate expansion and contraction leading to catastrophic flaking off of the entire consolidated layer. (For a discussion of the use of surface consolidants in the Australian context see Ambrose 1975; Walston 1975; and Walston and Dolanski 1976.)

The cover of loose sand provides a geochemical environment conducive to the survival of the buried engravings, at least in the short term. It can be seen from table 2 that when quartz $\left(\mathrm{SiO}_{2}\right)$ is left out of the calculations calcium is the only element which is higher in the buried calcarenite than in the sands. A positive geochemical gradient exists for all other components between the sand and the rock. Loss of components from the calcarenite is inhibited and the rock retains its structure and cohesiveness.

Any loss of calcium by dissolution and leaching of calcium carbonate from the calcarenite is countered by replacement by other components, especially magnesium, and therefore minimal' changes will take place within the rock. The mobility of elements between the the rock and its cover of sand is unlikely to be large because of the stabilising influence of a sulphate ion barrier near the rock surface. Because of this barrier, much of the calcium lost from the calcarenite will be precipitated in the sand adjacent to the rock face. Furthermore the accumulation at the rock surface of magnesium-rich 
compounds derived from sea-spray also acts to reduce the rate of chemical breakdown of the calcarenite. The $\mathrm{pH}$ of the loose sand is higher near the rock face than further from it, indicating that there is in fact some loss of carbonate from the rock into the sand by solution. The accumulation of these alkaline solution products then acts as a buffer, Eurther reducing the rate of solution at the rock surface. For these reasons we consider that the buried blocks of calcarenite should not undergo significant alteration over the next few decades.

An additional beneficial effect of the sand cover is that it protects the engravings from mechanical damage such as gravity induced granular and blocky disintegration of the rock outcrops, sandblasting, trampling by stock and vandalism.

Our conclusion is that although the rock is soft and friable and readily subject to mechanical breakdown if touched, it is not undergoing appreciable weathering through solution of the carbonate, or physical breakdown through salt crystallisation or sandblasting. Although we take cognisance of reports by earlier workers that many of the engravings are deteriorating rapidly, our examination of a series of photographs of the northem outcrop taken since 1931 (Meston 1933; Luckman 1951b; 1969 photographs supplied by Rhys Jones) indicates that those motifs which are visible at present have undergone no detectable deterioration in this time. This is also largely true of the now-buried motifs, when Luckman's photographs taken in 1949 (Luckman 1951b) are compared with those taken during the 1969 excavations.

\section{Coastal exosion}

In contrast to the relatively stable nature of the rock, the site is under considerable continuing long-term threat through coastal erosion. A comprehensive evaluation of this threat is dependent upon an understanding of the history and dynamics of the local shoreline and the blowout adjacent to the site. This is itself a major study, beyond the scope of this report, but the most important geomorphic factors can be broadly identified and their significance evaluated.

The extensive rocky shoreline to the north and the Mount Cameron West headland to the south provide effective barriers to the longshore movement of sand (fig. 1). Thus most of the sand now in the embayment originated through coastal aggradation as the sea approached and attained its present level about 7000 years ago. The equilibrium plan and profile of the beach system, which includes the foredune, beach and the offshore zone affected by wave activity, represent a balance between erosion of the beach and foredune at times of high wave energy, and aggradation at times of relative calm. Sand can be lost from the system either offshore when extreme storm wave activity carries it beyond the influence of the wave zone, or landward beyond the influence of storm waves, by aeolian transport.

The fact that there is an extensive active blowout adjacent to the site means that sand has been, and continues to be lost permanentzy from the beach system. This must inevitably result in the sea encroaching inland in order that the plan and profile of the beach system establish a new equilibrium. We are not able to detail the history of this blowout, but J. Stockton (pers. comm.) has examined maps of the region from the $1830 \mathrm{~s}$ until the 1950s, and comments that whilst large blowouts along the coast are generally marked on such maps, this bIowout is not indicated. Since the southern outcrop was almost totally exposed in the early $1930 \mathrm{~s}$, it is reasonable to infer that the blowout had al ready begun developing by that time, al though the presence of a scrub cover around the northern outcrop indicates that the northem maxgin of the blowout had not then encroached to its present position. It seems likely that the blowout began early this century, probably as a result of interference with the vegetation cover through clearance, burning and grazing, but that it remained smali until at least the $1940 \mathrm{~s}$.

The mean high water 1 imit is within a few metres of the engraving site. During severe storms the presently stable sand cover mantling the engravings could be eroded, or conceivably even be completely removed to expose the engraved rocks to wave erosion. If this coastline were to be affected by axceptionally severe storms in which surges (or 


\section{P.J. Hughes, A.L. Watchman and M.E. Sullivan}

high wave conditions) were also created, such as that which affected much of the New South Wales coastline in May 1974 (Foster et al. 1975), catastrophic erosion could easily occur.

\section{DISCUSSION}

Frovided stock are excluded from the site, shrubby plants with extended root systems are controlled, there is no inherent reason why the rock and its engravings should undergo significant deterioration over the next few decades. This is true of both the exposed and buried rock surfaces. The site should be left covered with a thick layer of sand until a long-term management plan is implemented, as this provides protection from accidental mechanical damage and vandalism.

Measures such as those outlined below are urgently needed to alleviate or prevent coastal erosion.

1. Stabilisation of the foredune system, especially along the front of the blowout.

This could be done through planting the presently eroded landforms with marram grass to encourage trapping of windblown sand within the beach system. However given the highly eroded nature of the foredune zone, it is unlikely that such planting will alone prevent the permanent loss of sand inland. A more effective measure would be to build up a foredune artificially, especially at the northern end, and plant this constructed dune with marram grass, to ensure that sand is trapped more efficiently in the beach system. It is essential that the sand used for this purpose be taken from the inland dunes, and not from the beach itself.

2. To minimise storm wave damage to the site itself, the blanket of sand mantling the engravings should be maintained, and preferably extended, also using sand brought from inland, and not from the adjacent beach. We note that Garry Melville has effectively stabilised the existing sand blanket and has erected a fence to keep out stock, and these measures have provided a sound basis for further management of the site.

3. Measures 1 and 2 will not be effective against exceptionally severe storms, and in the long-term (provided the site has not already been damaged in the meantime) the continued existence of the site can only be ensured through the construction of major coastal protection works along the beach, immediately in front of the site. Such construction works, which would be costly, would first require a major study of the coastal dynamics of the embayment. It is likely that such works would result in considerable changes in the longshore plan of the beach, especially to the south.

\section{CONCLUSTON}

U1timately the Service intends to prepare a long-term management plan involving conservation, presentation and interpretation of the site. Our conclusions on the geochemical environment of the engraving site, based as they are on limited fieldwork and analyses, may not provide an adequate basis for long-term site-specific management decisions. Before any management programe is implemented, for example possible reexcavation of the buried engravings for display, enclosure of the site in a protective shelter etc., more comprehensive and detailed studies of the calcarenite and its geochemical and hydrologic environment may be necessary. Coastal erosion control measures will have to be implemented as a first step in any management plan. Although some of these measures can be applied immediately, before a comprehensive erosion control programme can be designed a detailed study of the history and morphodynamics of the embayment will be necessary

\section{ACKNOWLEDGEMENTS}

This study was funcied by the National Parks and Wildlife Service of Tasmania. We particularly thank Greg Middleton for assisting with preparations for the fieldwork, and for providing the relevant documents. and Garry Melville for able assistance in the field. Rhys Jones and Bruce Thom discussed with us at length the results of this Study. Jim Stockton, Department of Prehistory, Research School of Pacific Studies, Australian National 
University, provided historical data and Winifred Mumford, of that department, drew the figure. SRD, IRS and XRF analyses were carried out in the Geology Department, Australian National University.

\section{REFERENCES}

Adams, J.E. and Rhodes, M.L., 1960: Dolomitization by seepage refluxion. Bul2. Amer. Assoc. Pet. Geol., $44: 1912-20$.

Ambrose, W.R., 1975: Rock art and its natural propensity for deterioration. In Edwards R. (Ed.): THE PRESERVATION OF' AUSTRALIA'S ABORIGINAL HERITAGE, pp. 104-7. Australian Aboriginal Studies No. 54, Australian Institute of Aboriginal Studies: Canberra.

Bauer, H.P., Beckett, P.H. and Bie, S.W., 1972: A rapid gravimetric method for estimating calcium carbonate in soils. Ptant and Soils, 37: 689-90

Folk, R.L., 1974: FETROLOGY OF SEDIMENTARY ROCKS. Hemphills, Austin, Texas.

Foster, D.N., Gordon, A.D., and Lawson, N.V., 1975: The storms of May-June 1974, Sydney, NSW. Proc. Coastal and Ocean Eng. Conference. Institution of Engineers, Australia, Gold Coast, Queensland, 1975.

Hughes, P.J., 1978: Weathering in sandstone shelters in the Sydney Basin and the survival of rock art. In Pearson, C. (Ed.): CONSERVATION OF ROCK ART. Institute for the Conservation of Cultural Material: Sydney.

, Watchman, A.L, and Sullivan, M.E., 1979: A geological and geomorphological investigation of the Mount Cameron West Aboriginal site, northwest Tasmania. National Parks and Wildlife Service, Tasmania, Unpub. Rep., September, 1979.

Jones, Rhys, in press: Rocky Cape, west Point and Mount Cameron west, nor.thwestern Tasmania. In THE HERITAGE OF AUSTRALIA: THE ILLUSTRATED REGISTER OF THE NATIONAL ESTATE. Macmillan, Melbourne.

Luckman, L.E., 195la: Some notes on the excavation of Aboriginal carvings at Mt Cameron West, Tasmenia. Unpublished report to the Royal Society of Tasmania.

1951b: The Aboriginal rock carvings at Mt Cameron west, Tasmania, photographs and notes on the excavations. Pap. Proc. R. Soc. Tasm: (1950): 25-7.

McCarthy, F.D., n.d.: The rock engravings of Mt Cameron West, North-West Tasmania. National Parks and Wildlife Service, Tasmania, Unpub. Manuscript.

Meston, A.I., 1933: Aboriginal rock carvings in Tasmania. Part II. Pap. Proe. R. Soc. Tasm.

1934: Aboriginal rock carvings in Tasmania. Antiquity 8: 179-84.

Muller, G. and Tietz, G., 1966: Recent dolomitization of quaternary biocalcarenites from Fuerteventura (Canary Islands). Contrib. Min. and Pet., 13: 89-96.

Norrish, K. and Hutton, J.T., 1969: An accurate X-ray spectrographic method for the analysis of a wide range of geological samples. Geochimica et Cosmochimica Acta, 33: $431-53$.

Richley, I.R., 1978: LAND SYSTEMS OF TASMANIA REGION 3. Tasmanian Department of Agriculture.

Shinn, E.A. and Ginsberg, R.N., 1964: Formation of recent dolomite in Florida and the Bahamas. Abstracts of the Buz2. Amer. Assoc. of Pet. Geol., 48: 547.

Taylor, G.F., 1975: The occurrence of monohydrocalcite in two small lakes in the southeast of South Australia. Amer. Min., 60:690-7.

walston, S., 1975: Rock art - deterioration and conservation. In Edwards, R. (Ed.): THE PRESERVATION OF AUSTRALIA'S ABORIGINAL HERITAGE, PP. 108-il. Australian Aboriginal Studies No. 54, Australian Institute of Aboriginal Studies: Canberra.

Walston, S. and Dolanski, J., 1976: Two painted and engraved sandstone sites in Australia. Studies in conservation, 21: 1-17. 